\title{
Article \\ Evaluating Public Transit Reforms for Shrinking and Aging Populations: The Case of Takamatsu, Japan
}

\author{
Masanobu Kii *D, Yuki Goda, Tetsuya Tamaki and Tatsuya Suzuki \\ Faculty of Engineering and Design, Kagawa University, Takamatsu 761-0396, Japan; \\ s20g402@stu.kagawa-u.ac.jp (Y.G.); tamaki.tetsuya@kagawa-u.ac.jp (T.T.); suzuki.tatsuya@kagawa-u.ac.jp (T.S.) \\ * Correspondence: kii.masanobu@kagawa-u.ac.jp
}

check for updates

Citation: Kii, M.; Goda, Y.; Tamaki,

T.; Suzuki, T. Evaluating Public

Transit Reforms for Shrinking and Aging Populations: The Case of Takamatsu, Japan. Future Transp. 2021, 1, 486-504. https://doi.org/ $10.3390 /$ futuretransp1030026

Academic Editor: Dan Graham

Received: 30 July 2021

Accepted: 31 August 2021

Published: 2 October 2021

Publisher's Note: MDPI stays neutral with regard to jurisdictional claims in published maps and institutional affiliations.

Copyright: (c) 2021 by the authors. Licensee MDPI, Basel, Switzerland. This article is an open access article distributed under the terms and conditions of the Creative Commons Attribution (CC BY) license (https:// creativecommons.org/licenses/by/ $4.0 /)$.

\begin{abstract}
Many small and midsized cities around the world are expected to experience rapid shrinking and aging of their populations in the near future. In Japan, these dramatic demographic shifts have already begun in all but the largest cities, creating an urgent need to redesign public transportation systems to accommodate the transit needs of smaller, older populations. Here we focus on the specific case of Takamatsu, a medium-sized city with a population of 420,000 that is currently redesigning its transit system to better serve an aging city with a declining working-age population. We use the agent-based transportation simulation model MATSim to predict the ramifications of Takamatsu's transit system reforms on transportation behavior in the year 2050. Our analysis reveals how the effects of Takamatsu's transit reforms vary geographically and temporally, with societal implications_-particularly for the mobility of elderly residents—-that we discuss.
\end{abstract}

Keywords: public transport; aging society; depopulation; agent-based simulation; land use and transport integration; transportation planning; transportation policy; urban planning

\section{Introduction}

The shrinking and aging of the populations of small and medium-sized cities is a phenomenon underway in many developed countries today [1,2], and predicted for developing countries over the next 30 to 50 years [3]. Among the various public policy issues posed by these rapid demographic shifts, one particularly urgent challenge is to reform and redesign existing public transportation networks to serve smaller, older societies. This task has been complicated in practice by the difficulty of predicting how transit system reforms will affect future transportation behavior. In this paper, we present a method for predicting the future performance of public transit systems, demonstrating the effectiveness of our method by applying it to the specific real-world example of transportation reform in Takamatsu, Japan.

The demographic trends mentioned above are exemplified in particular by many small and mid-sized cities in Japan, where rapidly declining birthrates and rapidly aging populations are significantly revising both the supply and demand sides of public transportation. On the demand side, cities with extensive motorization-driven sprawl see geographically thinning populations with growing cohorts of elderly citizens no longer able to drive- and thus face the challenge of providing public transportation services to meet increasing demand with decreasing spatial density. On the supply side, Japan's shrinking population of workers makes it more and more difficult to recruit drivers for labor-intensive public transportation services, where wages remain low due to the difficulty of providing value-added services to compete with automobiles. These changes have created an urgent need to reform and modernize Japan's transit systems.

A basic tenet of Japanese transportation policy is that public transportation services should be provided by an independently operating private sector. The government does provide subsidies - as a form of social welfare to ensure transportation is available to 
citizens without access to private vehicles—but subsidy amounts are limited in practice by persistent criticism of the injection of public funds into the private sector.

Thus, Japan's public transit systems must be reformed to achieve sustainability for an aging and declining population. Many municipalities have begun to address this challenge by formulating master plans, covering both transportation and land use, in accordance with national policy. These plans aim to maintain urban amenities amid shrinking populations by compactifying residential areas to increase population densities and interconnecting residential hubs via public transportation to improve access to key urban destinations. The objective of these initiatives is to preserve the quality of urban life despite declining populations, and public transportation reforms are central to achieving this goal.

As a specific example illustrating all of these general trends, this study focuses on one particular medium-sized Japanese city: the city of Takamatsu in Kagawa Prefecture, which in 2010 had a residential population of 420,000 and a working population of 230,000. In 2015, the Takamatsu City Office formulated a public transit master plan with two main initiatives: building new stations-to be developed as transportation nodes-on an existing rail line and reorganizing the network of bus routes into a trunk-feeder network serving the transportation nodes. The existing bus route network consists of long-distance lines running radially from the city center to the suburbs, with many sections running parallel to rail lines. The redesigned network aims to provide services better matched to demand, which varies by geographical sector (city center, near suburbs, or outer suburbs), and to extend a certain level of service to areas not currently accessible by public transit.

However, the quantitative impact of such reforms on the usability of public transportation is difficult to evaluate. In particular, the creation of new transit routes-and the elimination of old ones-affects different subregions in different ways, and the nature of these geographical variations must be understood before one can assess whether or not transit reforms have achieved their intended goals. One must also ensure that transportation policy remains consistent with land-use planning. To evaluate the usability of public transportation quantitatively; however, it is necessary to assess the public transportation routes and the set of the station and stop locations, frequency of service, and timetable. In addition, to evaluate the trunk feeder system of the public transport, it is necessary to consider the connection of the routes.

In this study, we apply MATSim (Multi-Agent Transport Simulation) [4], an agentbased traffic simulation model, to evaluate various measures of urban traffic, taking into account the factors discussed above. More specifically, we prepare MATSim models incorporating the spatial layouts and operating schedules of Takamatsu's transit networksbefore and after redesign — and use these models to simulate transportation choices made by Takamatsu residents. We analyze simulation results to characterize geographical variations in public transit availability - and how they impact demand for public transit servicesand apply this analysis to anticipate how transportation demand may evolve through 2050, touching on transit-policy issues of relevance for future aging societies.

Needless to say, the target of this study, a city in Japan, exhibits several specialized attributes reflecting conditions unique to Japan. (For example, in comparison to Europe, Japan has less stringent land-use restrictions and smaller public transit subsidies.) Nonetheless, we expect the findings of this study-with some revising of assumptions-will be of broad utility as a point of reference, simply because the challenge of public transit reform involves several common features. In particular, our methods are of direct relevance for analyzing transit policy in Asian cities seeking to address motorization-driven sprawl with limited transportation subsidies.

The remainder of this paper is organized as follows. Section 2 reviews relevant previous work. Section 3 discusses the subject of our analysis, input data sources, and scenarios for future projections. Section 4 describes our model and our method for calibrating it. Section 5 presents the results of our analysis, and Section 6 summarizes our conclusions and their ramifications for the design of sustainable public transit policies in aging societies. 


\section{Literature Review}

The reform of public transit systems has been the subject of many studies from various perspectives. A significant portion of these studies approach the design and scheduling of public transportation networks mathematically (as reviewed in [5]). However, the wide range of operating modes, legal systems, demand conditions, and policy requirements encountered in public transit systems requires that network-design problems be customized to address individual conditions in specific local contexts. For this reason, it is difficult to create general-purpose design tools for public transportation networks. In Japan, mathematical network-design techniques are rarely used; instead, experts and stakeholders design networks empirically, taking into account the specific constraints relevant for the particular situation at hand.

Redesigning transportation networks changes the usability of public transit systems and affects demand for public transportation [6]. Needless to say, demand for public transport does not depend solely on the quality of public transportation services, but is also greatly affected by the availability of automobiles and other factors. On the other hand, in highly automobile-dependent societies the social exclusion of people who cannot use automobiles becomes problematic, necessitating the provision of public transit services as a matter of policy [7]. In addition to young people commuting to school [8,9], policy measures are also needed to address the mobility of the elderly [10]. These studies have revealed the need to improve and promote public transportation and to plan the location of destination facilities for these populations. In developed countries, in particular, the growing number of older drivers has made road safety and mobility for the elderly an increasingly urgent issue [11-15]. In addition, some researchers have noted that the dependence of the elderly on cars can reduce their physical activity $[16,17]$ and affect their health [18-20]. In turn, the impact of mobility on quality of life for older citizens has also been examined [21-23]. These studies suggest that the need for public transportation will become more acute as societies age.

On a separate note, the privatization of public transport has been touted as a means of improving operational efficiency, increasing user convenience, and reducing public subsidies-but studies have also demonstrated that privatization does not always benefit users $[5,24]$. In regulated transport markets, transport operators generally receive subsidies and permission to wield monopoly powers, in return for which they are expected to cap fares and operate unprofitable routes [5]. On the other hand, in 2002, the Japanese government amended its Road Transport Act to relax entry regulations, allowing new operators to enter profitable routes and existing operators to withdraw from unprofitable routes; the new policy approach was quickly observed to have unanticipated consequences, including service reductions in areas-typically small- and medium-sized cities in remote areas of Japan - where operators were permitted to eliminate transit routes. (Similar effects have also been observed to follow deregulation in the United Kingdom [25].) Japan responded to this situation in 2020 by declaring that negotiations among multiple transportation operators were exempt from the Antimonopoly Law, making it possible for operators to discuss route restructuring for public transportation networks at public transportation advisory board meetings in local governments.

The upshot of these observations is that the behavior of transit operators cannot be explained by the simple economics of profit motives alone; one must also consider the dense thicket of legal conditions and political demands that constrain the provision of transit services. For this reason, the plethora of mathematically minded strategies that researchers have proposed for setting up networks and schedules-which include mathematical optimization [26], heuristic approaches [27], and genetic approaches [28,29] have been almost entirely ignored by Japanese practitioners, who choose instead to define transit routes via empirical methods capable of addressing situation-specific problems.

Some studies have used service schedule timetables-as prepared by transit operators themselves for use by customers-as sources of input data for transit system analysis. This approach has been facilitated in recent years by the many cities that have begun to offer 
timetable data in digitized form, with GTFS (general transit feed specification) emerging as a convenient standard format. One study employed GTFS data for Cincinnati to calculate travel times to shopping destinations, using the results to estimate the spatial distribution of food deserts based on the times of day at which they were reachable [30]. Another study in Helsinki used GTFS to obtain a Pareto set of transportation routes considering travel time, the number of transfers, and waiting time [31].

Also relevant to our work is the paradigm of Transit Oriented Development (TOD), a model of urban structure designed to take maximal advantage of public transit systems [32-35]. Since the efficiency of public transportation in a given region depends on the spatial distribution of users throughout the region, increasing the density of activity centers in the vicinity of transit stations can increase the use of public transportation and decrease dependence on automobiles. Transportation researchers and practitioners have noted the advantages of TOD ever since Calthorpe [32] proposed the concept in the late 1980s; for example, the recent example of Japanese land-use planning discussed above reflects the concept of TOD as a background.

The existing public transportation network in Takamatsu, our focus in this study, consists of long bus and rail lines emanating radially outward from the city center; these do not extend to population clusters in suburban areas, and it is difficult to adapt the level of service they provide to accommodate regional variations in demand. To address this situation, in 2015 Takamatsu's municipal government adopted a Regional Public Transport Network Formation Plan involving several initiatives: building two new stations on the existing Kotoden-Kotohira railroad line, developing these stations into local transit hubs, and reconfiguring the city's public transit network as a trunk feeder network linking railroads and buses. In this way, the project seeks to establish a newly reconstituted transit system closely fitted to the characteristic demand profiles observed in the city center, in suburban regions, and further afield.

However, the redesign of Takamatsu's transit network will naturally bring about changes in usability, and these changes will vary from place to place. In the current plan, the reformation of the transportation network remains a blueprint, and the impact on the usability has not been assessed. It is essential to understand the effects of the reformation to implement the plan and build consensus, and it is also necessary to consider measures to compensate for any decrease in usability caused by the reformation.

This study evaluates the impact and ramifications of the transit reform proposal currently under consideration in Takamatsu by analyzing the effects of the restructuring as felt in 2010 and in 2050 by a smaller, older population. We use MATSim to conduct agentbased microsimulations capable of analyzing user responses to geographical and temporal changes in usability; this capability is important, because network shapes and schedules have a dominant impact on usability, as previous studies have shown. To analyze the redesign of transit networks, we conduct sensitivity analyses for two possible scheduling scenarios (necessary as Takamatsu's plans do not yet specify a timeline for reforms). We also consider two distinct land-use scenarios: one in which suburbanization proceeds without impediment, and one in which land-use regulations are imposed to compactify the population distribution. A feature of our study is the detailed spatio-temporal insight it lends into the effects of transit reforms and land-use policies in aging Japanese cities-a valuable source of input for the design and evaluation of sustainable land-use and public transit policies in aging societies.

\section{Target Region, Input Data, Future Scenarios}

Figure 1 shows the location of the city of Takamatsu in Kagawa Prefecture, the focus of this study. The municipal government expects that the 2010 population of 420,000 will decrease to 370,000 by 2050, with the share of the population aged 65 and over growing from $23.2 \%$ to $37.1 \%$ over that period-making Takamatsu a vivid example of a shrinking, aging city. 


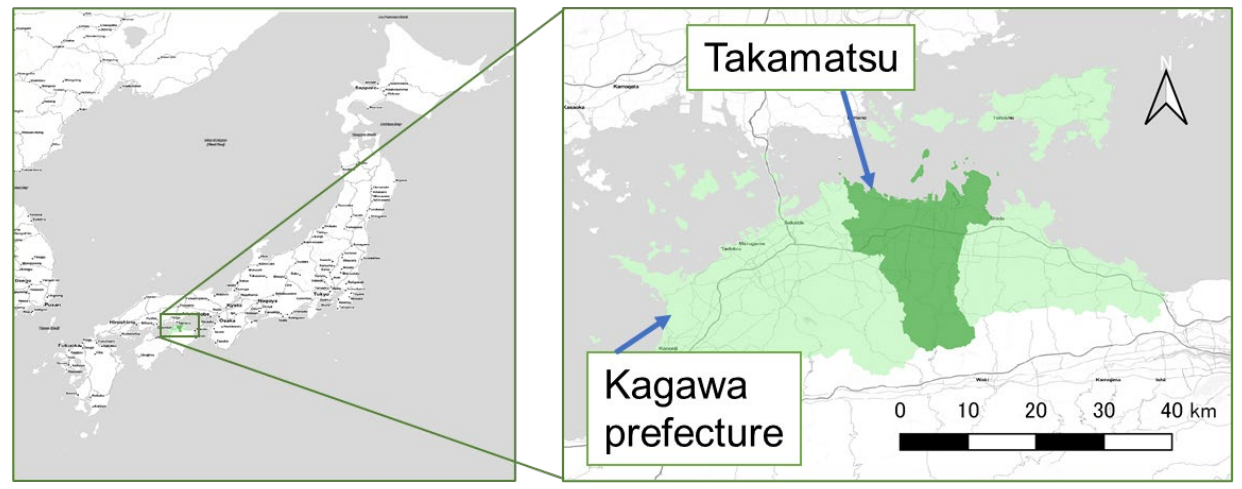

Figure 1. The focus of this study: the city of Takamatsu in Japan's Kagawa prefecture.

To characterize the spatial distribution of the current population, we use mesh-based population statistics based on the 2010 census. This dataset tabulates gender- and ageresolved population data on a geographical mesh with mesh elements of approximate size $500 \mathrm{~m}$ times $500 \mathrm{~m}$. To project future population distributions for 2050, we use SILO (Simple Integrated Land Use Orchestrator) [36,37], a micro land-use model that considers changes in households using the cohort-component method. We generate future population distributions under two distinct scenarios: the Business as Usual (BAU) scenario, in which trends toward suburbanization continue unchecked into the future, and the Draconic scenario, which imposes strict land-use regulations to achieve population compactness.

Figure 2 shows population distributions for Takamatsu City at present (left) and in the future under the BAU (center) and Draconic (right) scenarios. In the BAU scenario, the population in the city center decreases as suburbanization proceeds; in contrast, the Draconic scenario restricts the habitable area to the city center and two suburban cores.

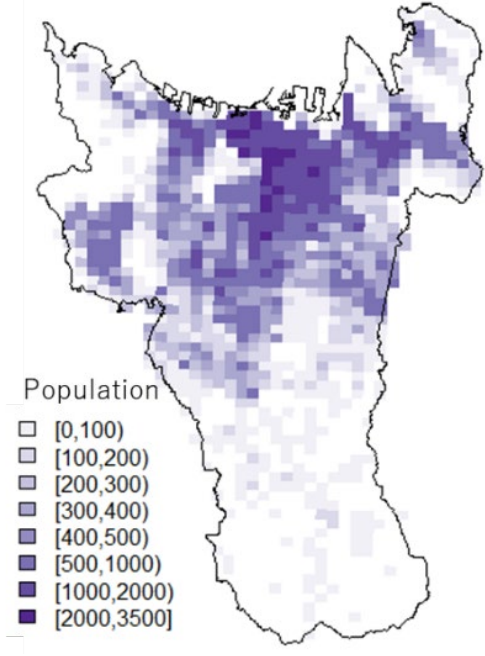

(a)

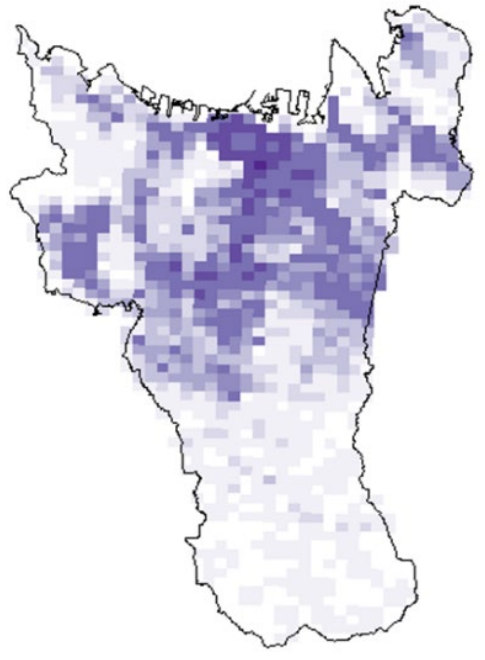

(b)

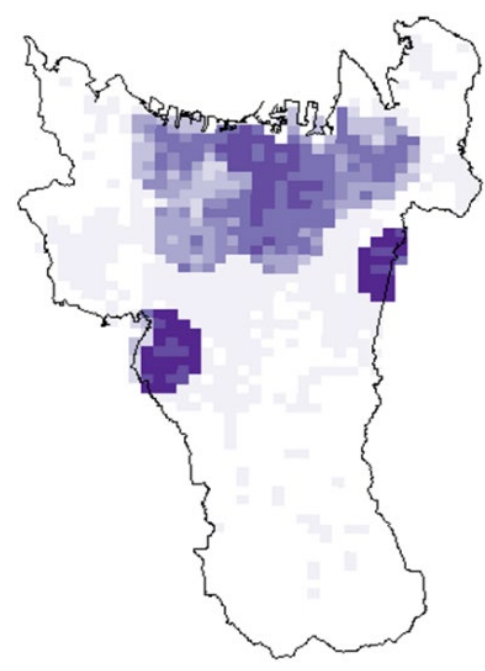

(c)

Figure 2. Nighttime spatial distribution of population in Takamatsu: (a) at present (2010); (b) in 2050 under the BAU (Business As Usual) scenario; (c) in 2050 under the Draconic scenario.

SILO models household location choices and estimates that, in the Draconic scenario, nighttime population densities in 2050 will be higher in the suburbs than in the city center; this reflects the concentration of residential locations in the suburbs, where real-estate prices are lower than in the city center due to broad swaths of regulated land. This example indicates that simple regulations on suburban development can produce highly nonuniform population distributions. The 2050 population of Takamatsu is estimated to be 330,000 in the BAU scenario and 310,000 in the Draconic scenario, with the difference being 
due to land-use restrictions and the corresponding dispersion of residential locations; note that both scenarios predict populations much smaller than the municipal government's estimate, mentioned above.

The 2012 Takamatsu Metropolitan Area Comprehensive Urban Transportation System Survey (denoted as the "Takamatsu Person-Trip Survey" or TPTS) reports a traffic volume of some 1.1 million trips per day to and from Takamatsu City, with $63.6 \%$ of trips made by private vehicles, $27.5 \%$ by walking or biking, and $6.7 \%$ by public transportation. Segregating transit use rates by age group, the survey finds that children (15 and under) and the elderly (65 and over) respectively use public transportation for $6.5 \%$ and $3.9 \%$ of their journeys, rates lower than the overall average; nonetheless, public transportation is recognized as a necessary option for those without access to private vehicles.

In this study, we approximate Takamatsu's existing public transit network and its operating schedules based on data from transport operators; this data was provided in the form of a GTFS dataset by one operator, and as digitized timetables by all other operators. In what follows we refer to this existing network as N0. To determine the bus route network of the redesigned future transit system we referred to materials prepared in 2016 for the advisory board of the Takamatsu City Regional Public Transportation Reformation Implementation Plan.

In this study, we assume that the redesign discontinues some existing bus routes, reducing the total length of bus routes from $919 \mathrm{~km}$ to $877 \mathrm{~km}$. To ensure that the total volume of service provided by the redesigned network (the total travel distance in vehicle-km) remained unchanged from that of $\mathrm{N} 0$, we compensated for the reduction in travel distance by increasing the frequency of routes. For this we considered two scenarios: case N1, in which only new bus routes in the redesigned network are assigned higher frequencies than routes in N0, and case $\mathrm{N} 2$, in which frequencies are increased for existing routes with high geographical density of demand. The total vehicle-distances traveled in our networks are $31,100 \mathrm{~km} /$ day for N0 and around 31,400 km/day for N1 and N2.

The geographical layouts of the existing and future public transportation networks, with daily link frequencies, are shown in Figure 3. Please note that N0 includes many direct routes from city center to suburbs, while N1 and N2 have more feeder routes in the east-west direction. Network N0 includes $919 \mathrm{~km}$ and 1584 links of public transport routes, while N1 and N2 include $877 \mathrm{~km}$ and 1492 links of public transport routes.

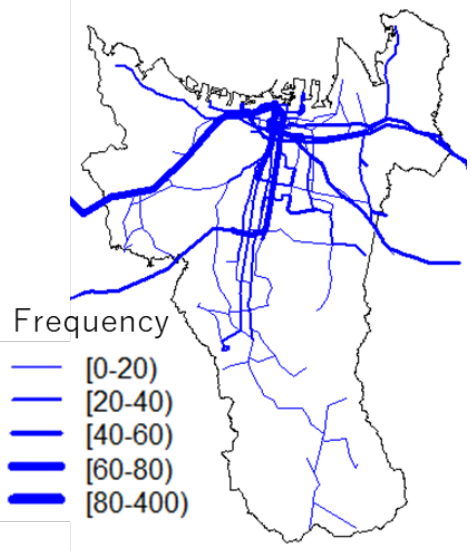

(a)

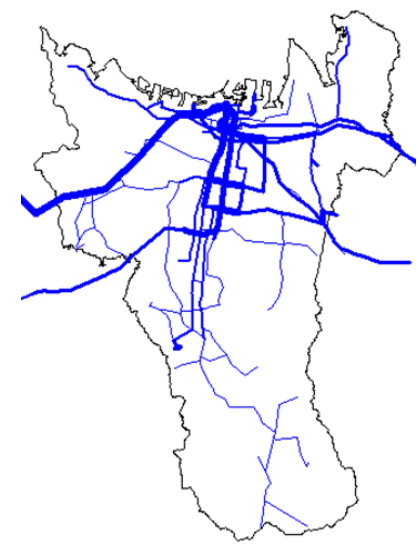

(b)

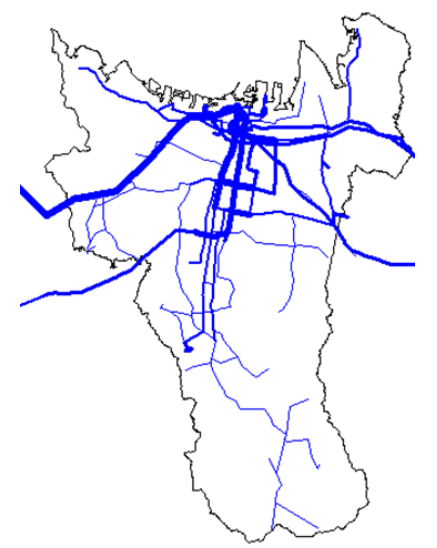

(c)

Figure 3. Geography and frequency of transit routes in Takamatsu's public transportation network. (a) At present (2010) (N0); (b) redesigned network with frequencies increased for new routes (N1); (c) redesigned network with frequencies increased for existing routes in high demand (N2).

We create road networks using Openstreetmap (https:/ /www.openstreetmap.org/, accessed on 29 August 2021). To account for both transit traffic and traffic flows into and out of Takamatsu, our network must encompass a broad spectrum of roads, from major 
highways traversing Kagawa Prefecture to narrow alleyways in downtown Takamatsu. As a result, the network used for our analysis contains $5337 \mathrm{~km}$ of roads and 18,540 links.

\section{Models and Calibration}

For each agent, MATSim requires a daily transportation plan consisting of an origin, a destination, and start and end times for activities at the destination. The agent chooses the departure time, the means of transportation, and the route to travel to obtain a high score for a given activity. The basic procedure of our demand estimation follows the orthodox four-step model [38], but we introduce some assumptions to simplify the analysis. At the same time, we introduce a sampling technique to convert the aggregated demand into MATSim inputs. In this section, we describe our method for choosing agent destinations for transportation plans and our technique for calibrating MATSim to match transportation assignments to the current situation.

\subsection{Generating Method of Transportation Plan}

In this study, we use a gravity-type model to generate origins and destinations for agents. We assume that the volume of traffic increases with increasing population at the origin and number of workers at destination and with decreasing distances between origins and destinations (ODs). The traffic volume is given by

$$
Q_{i j k}=\alpha_{k 0} N_{i k}^{\alpha_{k 1}} W_{j}^{\alpha_{k 2}} \exp \left(\theta_{k} D_{i j}\right)
$$

where $Q_{i j k}$ is the traffic volume of attribute $k$ between origin $i$ and destination $j, N_{i k}$ is the population of attribute $k$ at residence $i, W_{j}$ is the number of workers at destination $j, D_{i j}$ is the road network distance between $i j$, and $\alpha_{k 0}, \alpha_{k 1}, \alpha_{k 2}, \theta_{k}$ are parameters $\left(\theta_{k}<0\right)$. We determine parameter values separately for each agent attribute by maximizing a loglikelihood function:

$$
L L=-\sum_{i, j}\left(\overline{Q_{i j k}}-Q_{i j k}\right)^{2}
$$

Here $\overline{Q_{i j k}}$ is the OD traffic observed in the base year for the attribute in question. The parameter values obtained by this procedure are listed in Table 1.

\begin{tabular}{|c|c|c|c|c|c|c|c|c|c|}
\hline & & Parameter & & & & $t$-Value & & & \\
\hline & & $\alpha 0$ & $\alpha 1$ & $\alpha 2$ & $\theta$ & $\alpha 0$ & $\alpha 1$ & $\alpha 2$ & $\theta$ \\
\hline \multirow{15}{*}{ Male } & $5-9$ & $2.07 \times 10^{-4}$ & 0.870 & 1.020 & -0.342 & 5.55 & 33.53 & 45.27 & -44.66 \\
\hline & $10-14$ & $5.20 \times 10^{-6}$ & 0.738 & 1.465 & -0.267 & 8.02 & 34.12 & 83.05 & -51.75 \\
\hline & 15-19 & $5.28 \times 10^{-4}$ & 0.394 & 1.092 & -0.251 & 5.04 & 20.97 & 48.94 & -39.48 \\
\hline & $20-24$ & $4.74 \times 10^{-3}$ & 0.614 & 0.586 & -0.117 & - & 22.67 & 38.83 & -29.44 \\
\hline & $25-29$ & $1.65 \times 10^{-3}$ & 0.408 & 0.906 & -0.204 & 7.94 & 21.71 & 52.18 & -30.62 \\
\hline & $30-34$ & $5.01 \times 10^{-3}$ & 0.489 & 0.727 & -0.170 & 6.55 & 27.37 & 40.36 & -35.89 \\
\hline & $35-39$ & $1.53 \times 10^{-2}$ & 0.494 & 0.657 & -0.200 & - & 32.32 & - & -40.42 \\
\hline & $40-44$ & $2.01 \times 10^{-1}$ & 0.401 & 0.399 & -0.164 & 13.49 & 21.88 & 29.93 & -31.77 \\
\hline & $45-49$ & $3.48 \times 10^{-2}$ & 0.431 & 0.544 & -0.136 & 4.45 & 22.20 & 24.82 & -37.78 \\
\hline & $50-54$ & $2.01 \times 10^{-2}$ & 0.670 & 0.471 & -0.156 & 9.17 & 32.29 & 31.73 & -39.31 \\
\hline & $55-59$ & $3.51 \times 10^{-2}$ & 0.839 & 0.331 & -0.195 & 17.64 & 33.98 & 20.93 & -33.47 \\
\hline & $60-64$ & $1.26 \times 10^{-3}$ & 0.921 & 0.683 & -0.199 & - & - & - & -49.51 \\
\hline & $65-69$ & $8.07 \times 10^{-4}$ & 1.396 & 0.486 & -0.256 & - & 69.17 & 36.18 & -48.67 \\
\hline & $70-74$ & $1.39 \times 10^{-4}$ & 0.602 & 1.156 & -0.236 & 11.96 & 22.35 & 68.01 & -47.28 \\
\hline & Over 75 & $2.37 \times 10^{-2}$ & 0.827 & 0.423 & -0.247 & - & - & - & -47.04 \\
\hline
\end{tabular}

Table 1. Results of parameter estimation for the gravity model. 
Table 1. Cont.

\begin{tabular}{|c|c|c|c|c|c|c|c|c|c|}
\hline & & Parameter & & & & $t$-Value & & & \\
\hline & & $\alpha 0$ & $\alpha 1$ & $\alpha 2$ & $\theta$ & $\alpha 0$ & $\alpha 1$ & $\alpha 2$ & $\theta$ \\
\hline \multirow{15}{*}{ Female } & $5-9$ & $1.43 \times 10^{-2}$ & 0.569 & 0.787 & -0.432 & 3.38 & 27.85 & 22.92 & -38.40 \\
\hline & $10-14$ & $1.15 \times 10^{-2}$ & 1.383 & 0.276 & -0.369 & 3.09 & 33.52 & 9.46 & -35.23 \\
\hline & $15-19$ & $6.22 \times 10^{-2}$ & 0.406 & 0.521 & -0.182 & 14.81 & 20.27 & 41.09 & -33.54 \\
\hline & $20-24$ & $8.53 \times 10^{-4}$ & 0.631 & 0.857 & -0.233 & 10.19 & 22.89 & 47.39 & -30.25 \\
\hline & $25-29$ & $2.02 \times 10^{-3}$ & 0.649 & 0.772 & -0.201 & - & 32.50 & 89.74 & -40.00 \\
\hline & $30-34$ & $1.72 \times 10^{-3}$ & 0.727 & 0.850 & -0.344 & 5.47 & 35.58 & 39.89 & -45.09 \\
\hline & $35-39$ & $3.90 \times 10^{-2}$ & 0.636 & 0.571 & -0.295 & 16.49 & 32.18 & 40.07 & -38.38 \\
\hline & $40-44$ & $2.17 \times 10^{-1}$ & 0.542 & 0.441 & -0.294 & 11.08 & 28.75 & 30.14 & -35.77 \\
\hline & $45-49$ & $6.79 \times 10^{-4}$ & 1.131 & 0.640 & -0.234 & 5.40 & 39.67 & 31.29 & -42.70 \\
\hline & $50-54$ & $3.43 \times 10^{-3}$ & 0.786 & 0.691 & -0.247 & 15.14 & 37.02 & 47.93 & -45.81 \\
\hline & $55-59$ & $3.27 \times 10^{-4}$ & 0.882 & 0.869 & -0.216 & - & 40.10 & 70.45 & -51.46 \\
\hline & $60-64$ & $5.20 \times 10^{-3}$ & 0.908 & 0.586 & -0.237 & 9.56 & 40.22 & 37.65 & -49.41 \\
\hline & $65-69$ & $1.51 \times 10^{-4}$ & 0.435 & 1.259 & -0.263 & 15.23 & 15.63 & 69.60 & -40.54 \\
\hline & $70-74$ & $1.06 \times 10^{-2}$ & 0.701 & 0.684 & -0.390 & 5.54 & 24.30 & 32.39 & -34.59 \\
\hline & Over 75 & $8.98 \times 10^{-3}$ & 1.218 & 0.250 & -0.358 & 2.74 & 27.42 & 12.74 & -42.96 \\
\hline
\end{tabular}

The estimated parameter values for all attributes satisfy the sign condition. Most parameters are statistically significant, but the $t$-values of some parameters are not properly estimated. Our parameter-estimation methods leave room for improvement-for example, age group categories could be aggregated-but this is a topic for future work.

We obtain average parameter values for all ODs by minimizing Equation (2). To ensure that OD traffic estimates agree with observed data, we introduce an adjustment term $\delta_{i j k}$ chosen to satisfy the following equation for each OD and each attribute:

$$
\hat{Q_{i j k}}=\alpha_{k 0}^{*} N_{i k}^{\alpha_{k 1}^{*}} W_{j}^{\alpha_{k 2}^{*}} \exp \left(\theta_{k}^{*}\left(D_{i j}+\delta_{i j k}\right)\right)
$$

Here $\alpha_{0}{ }^{*}, \alpha_{1}{ }^{*}, \alpha_{2}{ }^{*}, \theta^{*}$ are the parameter estimates. Solving Equation (3) for $\delta_{i j k}$ yields

$$
\delta_{i j k}=\frac{1}{\theta^{*}} \ln \left(\frac{\overline{Q_{i j k}}}{\alpha_{0}^{*} N_{i k}^{\alpha_{1}^{*}} W_{j}^{\alpha_{2}^{*}}}\right)-D_{i j}
$$

This shows that, as long as $\delta^{*}$ is non-zero and the logarithm of the quantity in parentheses can be computed, there is a uniquely defined value to which $\delta_{i j k}$ may be tuned to ensure exact agreement between estimates and observations. However, OD traffic volumes are given only for zones in the TPTS. In this study, the zones are given by mesh, so the adjustment factor is applied to the mesh zone whose center of gravity is within the person-trip zone. Furthermore, we assume the volume of trip generation is given as described below, and the destination choice probability $P_{k}(j \mid i)$ is given by the following equation using the OD traffic volume $\hat{Q_{i j k}}$ estimated using the above parameters and the adjustment factor.

$$
P_{k}(j \mid i)=\frac{\hat{Q_{i j k}}}{\sum_{j} \hat{Q_{i j k}}}
$$

This formulation is an attempt to estimate the OD demand by mesh zone. When the population and employment numbers of the mesh zone are applied to Equation (3), the conservation law of travel demand by PTPS zone is not necessarily satisfied. Therefore, we approximate the attractiveness of the destination zone by the OD traffic volume estimated 
in Equation (3), and estimate the destination share in Equation (5). Then, by multiplying the share of destinations and trip generation by the agent, we estimate the travel demand for OD. We assume that all agents make at least one trip per day from their home and return home from their destination. We determine each agent's times of departure from home and destination by random sampling from PTPS data for each segment of the agent. We also assume that some agents of working age (15 to 64) make business trips; we determine the (present-day) volume of business traffic as the difference between the road-traffic volume estimated from the 2010 Road Traffic Census and the traffic volume to/from home estimated by our model. To estimate the future volume of business traffic, we assume that the ratio of business traffic to home traffic for working-age agents does not change from 2010 to 2050; then the future business-traffic volume is obtained by multiplying the present-day business-traffic volume by the ratio of the 2050 and 2010 working-age populations. OD pairs for business traffic are sampled from the OD pairs to/from home calculated above. We set departure times for business traffic by sampling home-related trips for the working-age population.

To exclude walking and bicycle journeys from our analysis, we first create a modechoice logit model [39] with three transportation-mode options: car, public transportation, and walking/bicycling. In this model, the probability $P r_{i j k}(m)$ that an agent of attribute $k$ chooses transportation mode $m$ to travel from origin $i$ to destination $j$ is

$$
\operatorname{Pr}_{i j k}(m)=\frac{\exp \left(V_{i j k m}\right)}{\sum_{m^{\prime}=\{c a r, p t, w a l k\}} \exp \left(V_{i j k m^{\prime}}\right)}
$$

where $V_{i j k m}$ is the utility of mode $m$ for the $i \rightarrow j$ journey, defined by

$$
V_{i j k m}=\beta_{k m}+\beta_{k 1} T_{i j m}
$$

where $T_{i j m}$ is the time required for the $i \rightarrow j$ journey via mode $m$ and $\beta_{k m}, \beta_{k 1}$ are parameters. Denoting by $R_{i j k}(m)$ the observed value of the share of $i \rightarrow j$ journeys completed via mode $m$, the parameters are calculated to maximize a log-likelihood function of the form

$$
L L\left(\boldsymbol{\beta}_{k}\right)=\sum_{i j, m} R_{i j k}(m) \ln P r_{i j k}\left(m \mid \boldsymbol{\beta}_{k}\right)
$$

with $\beta_{k}=\left\{\beta_{k 1}, \beta_{k, p t}, \beta_{k, \text { walk }}\right\}$. Having determined values for $\boldsymbol{\beta}_{k}$, we introduce an adjustment term $\tau_{i j k m}$ for the utility of each mode and choose its value to maximize the modified likelihood function

$$
L L\left(\tau_{i j k}\right)=\sum_{m} R_{i j k}(m)\left(V_{i j k m}+\tau_{i j k m}\right)-\ln \sum_{m} \exp \left(V_{i j k m}+\tau_{i j i k m}\right),
$$

after which the mode-choice probabilities are given by

$$
\operatorname{Pr}_{i j k}(m)=\frac{\exp \left(V_{i j k m}+\tau_{i j k m}\right)}{\sum_{m^{\prime}=\{c a r, p t, w a l k\}} \exp \left(V_{i j k m^{\prime}}+\tau_{i j k m^{\prime}}\right)}
$$

Table 2 lists values of $\boldsymbol{\beta}_{k}$ obtained for each gender and age group. 
Table 2. Results of parameter estimation for the transportation mode choice model.

\begin{tabular}{|c|c|c|c|c|c|c|c|}
\hline & & Parameter & & & $t$-Value & & \\
\hline & & $\beta_{1}$ & $\beta_{p t}$ & $\beta_{\text {walk }}$ & $\beta_{1}$ & $\beta_{p t}$ & $\beta_{\text {walk }}$ \\
\hline \multirow{15}{*}{ Male } & $5-9$ & $-7.61 \times 10^{-3}$ & -3.72 & 1.11 & -97.5 & -28.5 & 163.5 \\
\hline & $10-14$ & $-9.21 \times 10^{-3}$ & -4.14 & 2.48 & -97.3 & -12.1 & 260.8 \\
\hline & $15-19$ & $-1.06 \times 10^{-2}$ & 0.30 & 2.74 & -77.8 & 12.5 & 130.5 \\
\hline & $20-24$ & $-1.73 \times 10^{-2}$ & -2.44 & 0.74 & -60.5 & -31.3 & 34.6 \\
\hline & $25-29$ & $-1.21 \times 10^{-2}$ & -2.79 & 0.11 & -62.1 & -37.5 & 8.4 \\
\hline & $30-34$ & $-2.30 \times 10^{-2}$ & -1.95 & 0.78 & -84.4 & -40.5 & 50.9 \\
\hline & $35-39$ & $-2.32 \times 10^{-2}$ & -2.90 & 0.33 & -90.2 & -37.6 & 25.7 \\
\hline & $40-44$ & $-1.56 \times 10^{-2}$ & -2.65 & -0.03 & -78.9 & -51.6 & -2.5 \\
\hline & $45-49$ & $-2.21 \times 10^{-2}$ & -2.40 & 0.45 & -83.0 & -43.2 & 29.0 \\
\hline & $50-54$ & $-1.63 \times 10^{-2}$ & -2.41 & 0.21 & -67.0 & -48.3 & 13.6 \\
\hline & $55-59$ & $-1.39 \times 10^{-2}$ & -3.24 & -0.08 & -75.8 & -42.4 & -6.5 \\
\hline & $60-64$ & $-1.43 \times 10^{-2}$ & -4.07 & 0.07 & -131.6 & -35.7 & 8.8 \\
\hline & $65-69$ & $-7.67 \times 10^{-3}$ & -4.56 & -0.31 & -86.8 & -33.4 & -42.3 \\
\hline & $70-74$ & $-1.10 \times 10^{-2}$ & -4.50 & 0.11 & -120.1 & -28.7 & 15.4 \\
\hline & Over 75 & $-9.77 \times 10^{-3}$ & -4.56 & 0.14 & -135.1 & -28.9 & 24.1 \\
\hline \multirow{15}{*}{ Female } & $5-9$ & $-6.95 \times 10^{-3}$ & -5.80 & 1.01 & -85.8 & -5.9 & 145.4 \\
\hline & $10-14$ & $-4.02 \times 10^{-3}$ & -3.03 & 2.07 & -48.3 & -34.8 & 262.6 \\
\hline & $15-19$ & $-1.17 \times 10^{-2}$ & 0.63 & 2.51 & -68.8 & 27.0 & 101.2 \\
\hline & $20-24$ & $-1.43 \times 10^{-2}$ & -1.69 & 0.58 & -70.6 & -49.4 & 37.0 \\
\hline & $25-29$ & $-2.92 \times 10^{-2}$ & -1.80 & 0.45 & -54.8 & -42.3 & 20.8 \\
\hline & $30-34$ & $-2.86 \times 10^{-2}$ & -3.80 & 0.55 & -117.6 & -21.8 & 51.8 \\
\hline & $35-39$ & $-2.34 \times 10^{-2}$ & -3.16 & 0.20 & -119.0 & -49.0 & 20.6 \\
\hline & $40-44$ & $-2.95 \times 10^{-2}$ & -3.68 & 0.46 & -149.8 & -29.3 & 52.7 \\
\hline & $45-49$ & $-2.99 \times 10^{-2}$ & -2.35 & 0.51 & -106.5 & -58.2 & 41.2 \\
\hline & $50-54$ & $-2.69 \times 10^{-2}$ & -3.63 & 0.52 & -140.8 & -29.2 & 50.8 \\
\hline & $55-59$ & $-1.83 \times 10^{-2}$ & -3.44 & 0.38 & -127.5 & -41.0 & 38.8 \\
\hline & $60-64$ & $-1.63 \times 10^{-2}$ & -4.36 & 0.30 & -161.2 & -28.3 & 42.3 \\
\hline & $65-69$ & $-1.30 \times 10^{-2}$ & -4.13 & 0.48 & -147.9 & -30.6 & 69.0 \\
\hline & $70-74$ & $-9.73 \times 10^{-3}$ & -4.68 & 0.58 & -130.6 & -18.2 & 92.8 \\
\hline & Over 75 & $-1.11 \times 10^{-2}$ & -3.88 & 0.87 & -139.9 & -29.4 & 134.4 \\
\hline
\end{tabular}

The utility function above is quite simple, using only travel time as an explanatory variable. Usually, mode choice models use the cost of travel and mode-specific factors such as ridership and congestion. Some studies also consider the impact of socioeconomic factors such as income, household size, and demographics on mode choice. Our study focuses on changes in travel time due to the redesign of public transportation networks and does not consider changes in transportation costs or fares. Furthermore, it does not consider socioeconomic changes other than demographics and residential location. Rather, we focus on the effects of population decline and aging. Therefore, we estimated a mode choice model for each age and gender segment. This segmentation allows us to reflect demographic changes in the estimation of future mode choice. 
Using these models, we estimate OD traffic volumes—by modes other than walkingfor the current and future populations, then create transportation plans for MATSim. The total number of trips per day was estimated to be 1,185,000 in 2010, 876,000 in 2050 under BAU, and 777,000 in 2050 under Draconic. The projected 2050 populations of Takamatsu are 330,000 under BAU and 310,000 under Draconic. Fewer trips per capita are predicted for Draconic than for BAU, reflecting the greater prevalence of walking and biking in the Draconic scenario.

\subsection{Calibration of MATSim}

In this study, we also use MATSim to estimate transportation choices made by agents. A parameter of the car use in MATSim was adjusted to reproduce the observed share of car and public transportation in 2012 to and from Takamatsu City. The number of agents used in the simulation was $10 \%$ of the population, and the scaling factor for traffic capacity was adjusted to reproduce the average daily road speed in 2010 .

After this calibration, the model estimate for the ratio of car trips to public transit trips is 0.91:0.09, to be compared to the observed ratio of 0.90:0.10; the model estimate for the $12 \mathrm{~h}$ average travel speed in Takamatsu is $30.5 \mathrm{~km} / \mathrm{h}$, to be compared to the observed value of $31.3 \mathrm{~km} / \mathrm{h}$ reported by the Road Traffic Census. Thus, our calibration technique enables the model to represent average traffic conditions with reasonable accuracy.

\section{Results}

We used MATSim to predict the transportation-mode ratios and average travel times, distances, and speeds expected in 2050 under the various population evolution and transit reform scenarios discussed in Section 3, with results tabulated in Table 3.

Table 3. Simulation results.

\begin{tabular}{|c|c|c|c|c|c|c|c|c|c|c|}
\hline & \multirow{2}{*}{$\begin{array}{c}\text { Population Scenarios } \\
\text { Network Scenarios }\end{array}$} & \multicolumn{3}{|c|}{2010} & \multicolumn{3}{|c|}{2050} & \multicolumn{3}{|c|}{ 2050_Draconic } \\
\hline & & No & N1 & N2 & No & N1 & N2 & No & N1 & N2 \\
\hline \multirow{4}{*}{ Uี } & Share & 0.907 & 0.889 & 0.891 & 0.928 & 0.914 & 0.914 & 0.922 & 0.904 & 0.904 \\
\hline & Average travel time (second) & 998 & 989 & 1.008 & 825 & 834 & 833 & 878 & 877 & 868 \\
\hline & Average travel length (meter) & 11.164 & 11.295 & 11.280 & 10.778 & 10.884 & 10.881 & 10.425 & 10.519 & 10.522 \\
\hline & Average speed $(\mathrm{km} / \mathrm{h})$ & 40.3 & 41.1 & 40.3 & 47.0 & 47.0 & 47.0 & 42.7 & 43.2 & 43.7 \\
\hline \multirow{4}{*}{ 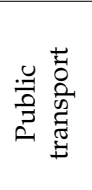 } & Share & 0.093 & 0.111 & 0.109 & 0.072 & 0.086 & 0.086 & 0.078 & 0.096 & 0.096 \\
\hline & Average travel time (second) & 2.310 & 2.155 & 2.159 & 2.208 & 2.095 & 2.099 & 2.261 & 2.161 & 2.202 \\
\hline & Average travel length (meter) & 5.158 & 4.918 & 4.921 & 4.762 & 4.669 & 4.645 & 4.789 & 4.749 & 4.844 \\
\hline & Average speed $(\mathrm{km} / \mathrm{h})$ & 8.0 & 8.2 & 8.2 & 7.8 & 8.0 & 8.0 & 7.6 & 7.9 & 7.9 \\
\hline
\end{tabular}

We first note that the redesign of public transportation networks under the 2010 population increases the share of trips using public transportation from its present value of $9 \%$ to $11 \%$, while reducing the average time and distance of public transit journeys by $7 \%$ and $5 \%$, respectively. The average travel speeds for $\mathrm{N} 1$ and $\mathrm{N} 2$ are $2 \%$ faster than that of N0, although we note that these speeds are calculated based on total travel times and distances, including both transit and walking trips. On the other hand, the average distance traveled by private vehicles increases by about $1 \%$ in both scenarios, with average travel time decreasing slightly in N1 and increasing slightly in N2. As a result, the N1 scenario yields a slight improvement on average speed, while the average speed in N2 is nearly unchanged from its current (N0) value.

Next, under the BAU scenario, the share of trips using public transport in 2050 is predicted to decrease relative to 2010 values-to $7.2 \%$ for N0 and $8.6 \%$ for N1 and N2. This decrease in public transport use has two causes: reduced access to public transportation due to suburbanization and higher car-travel speeds made possible by the reduction in road traffic accompanying population decline. Indeed, under BAU the average road-traffic 
speed is $47 \mathrm{~km} / \mathrm{h}$ in 2050 - an increase of $17 \%$ over 2010 values—while the average speed of public transportation decreases by $3 \%$ over the 40 -year interval. This finding may reflect increased distances of access to and egresses from the public transport, as well as an increase in transfers.

The Draconic scenario also predicts a decrease in public transit use from 2010 to 2050, but the magnitude of the decline is smaller in this case than in the BAU scenario. This reflects the relatively lower road-traffic speed predicted for Draconic as compared to BAU, as well as the higher probability of choosing public transport due to the geographical concentration of residential locations. However, the average speed of public transportation is also lower for Draconic than for BAU, due to longer access, egress, and transit times; thus, this scenario cannot be considered an implementation of TOD principles. In the Draconic scenario, the share of journeys made by public transport decreases to $7.8 \%$ if the public transportation network is left unchanged (the N0 case), but remains near $9.6 \%$ if the network is redesigned (N1, N2 cases).

Figures 4 and 5, respectively, show the average travel time for public transit journeys and the average speed of road transportation. Travel times for public transportation are shorter in the redesigned networks (N1/N2, dashed curves) than in the existing network (N0, solid curves). Waiting and access times are longer in the early morning due to the lower route frequencies, but after 8 a.m., we see that travel times remain nearly unchanged throughout the day. At most times of day, the shortest travel times occur in the N1 and N2 variants of the BAU case. In these scenarios, road speeds are relatively high, and journeys that are time-consuming by public transportation are most often made by car-leaving public transport to be used only for shorter trips.

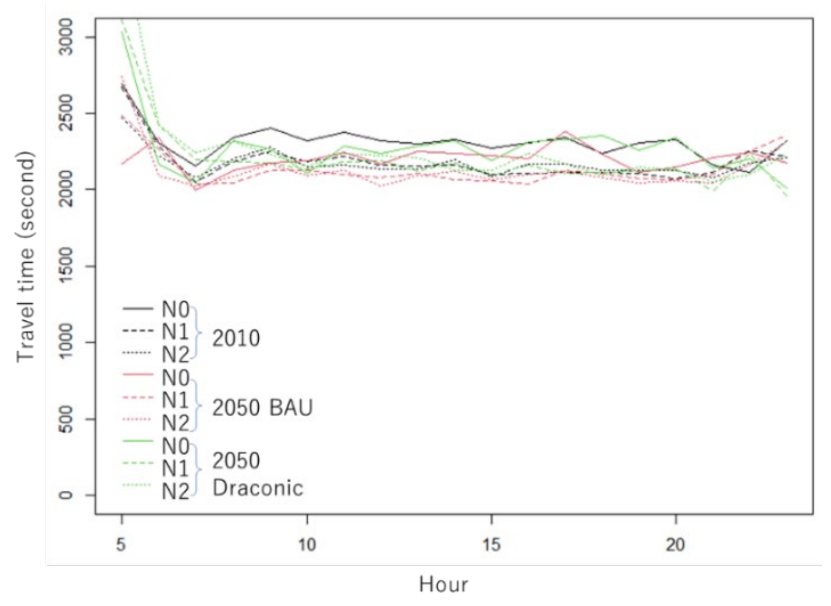

Figure 4. Average travel time vs. departure time for public transport journeys.

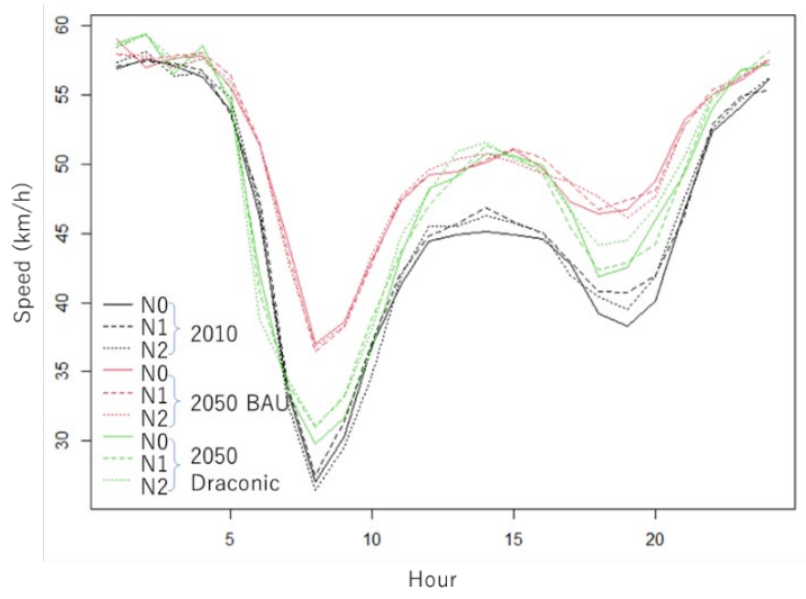

Figure 5. Average road travel speed vs. departure time. 


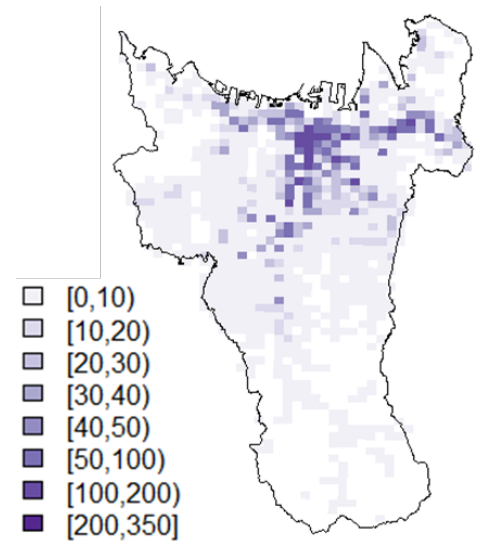

(a)

Figure 6 shows the spatial distribution of public transportation users-at their departure points-for the case of the N0 network. The overall number of users decreases from 2010 to 2050, but the characteristics of the spatial distribution - specifically, the presence of large numbers of users in central areas, with fewer users in suburban areas-remainsunchanged.

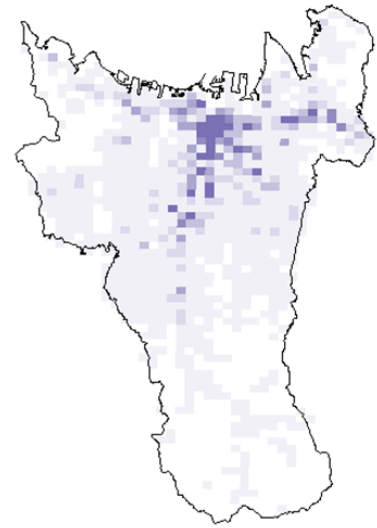

(b)

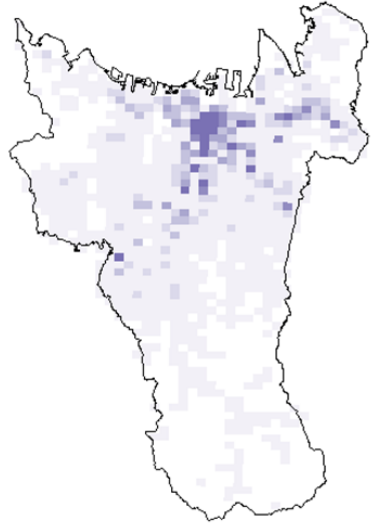

(c)

Figure 6. Spatial distribution of public transportation users for the N0 transit network: (a) at present (2010); (b) 2050 BAU; (c) 2050 Draconic. The value plotted for each mesh square indicates the number of transit users whose departure point lies in the square.

The quantity plotted in Figure 7 is the difference between the Draconic-predicted and BAU-predicted numbers of public transit trips, assuming network scenarios N0 (left), N1 (center), and N2 (right). In these plots, red pixels indicate locations from which more public transportation journeys are expected to originate under BAU than under Draconic; blue pixels indicate locations from which more journeys are expected under Draconic. For all network scenarios, we observe a proliferation of red pixels near the city center and of blue pixels in suburban regions, indicating fewer transit journeys predicted to originate from the city center-and more predicted to originate from suburbs-for Draconic compared to BAU. However, the difference is relatively small for N0, and the decrease in the number of trips from the city center appears larger in N1. In the Draconic scenario, the spatial dispersion of residential locations results in low traffic volumes; population growth in suburban areas then spurs an increase in public transportation trips from suburbs, with fewer trips originating from the city center.

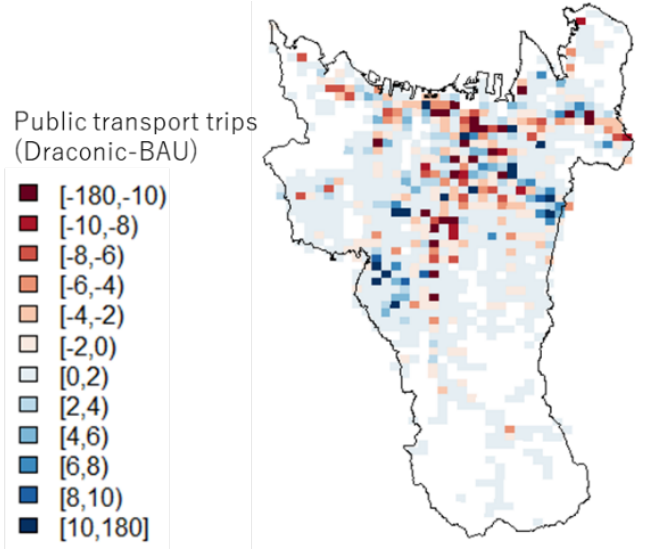

(a)

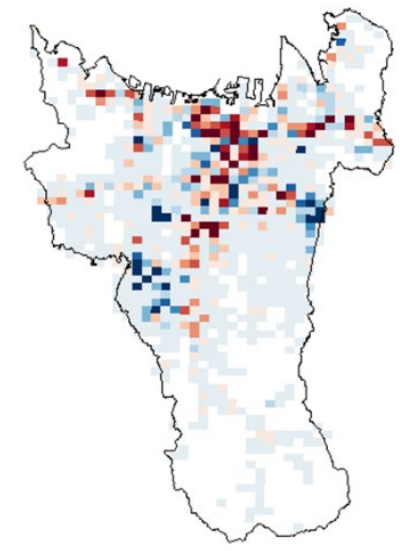

(b)

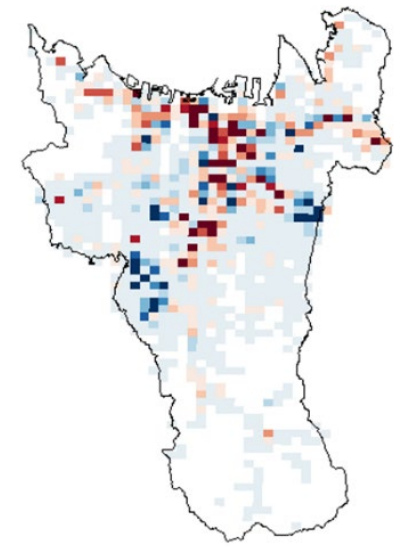

(c)

Figure 7. Plots indicating the difference between the numbers of public transport trips predicted under Draconic and BAU scenarios for network scenarios (a) N0; (b) N1; (c) N2. Red pixels indicate locations from which more public transit journeys are predicted to originate under BAU than under Draconic; blue pixels indicate more journeys predicted under Draconic than BAU. 
Figure 8 shows the difference in the number of transit passengers predicted with and without network redesign for the BAU and Draconic scenarios. Figure $8 \mathrm{a}, \mathrm{b}$ show the difference in the number of passengers per day predicted by N1 and N2 of the network redesign scenario and $\mathrm{N} 0$ of the baseline scenario for the BAU case. Here the blue line shows the links where the number of passengers is expected to be higher in N1 or N2 than in N0, and the red line shows the links where the number of passengers is higher in N0. Figure $8 \mathrm{c}$,d show a similar plot for the Draconic scenario. The newly added links under the redesigned network have a significant transport demand, but some peripheral links have a decline of passengers due to the network redesign. No significant difference is seen between the results for $\mathrm{N} 1$ and $\mathrm{N} 2$. We observe a significant increase in the number of users of some suburban transit links in the Draconic scenario compared to the BAU scenario.

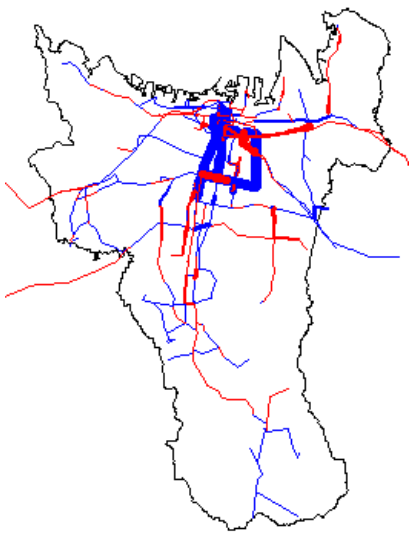

(a)

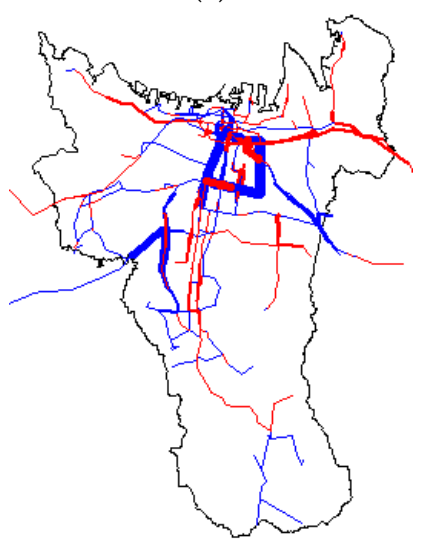

(c)

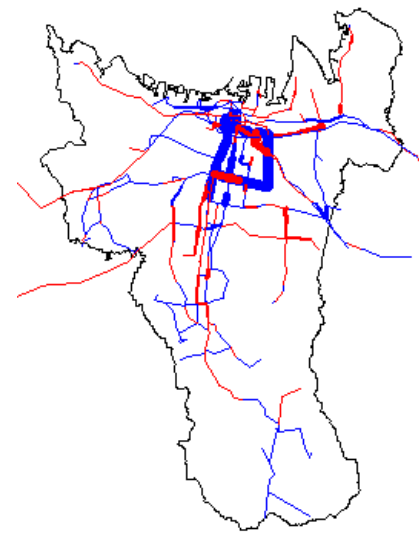

(b)

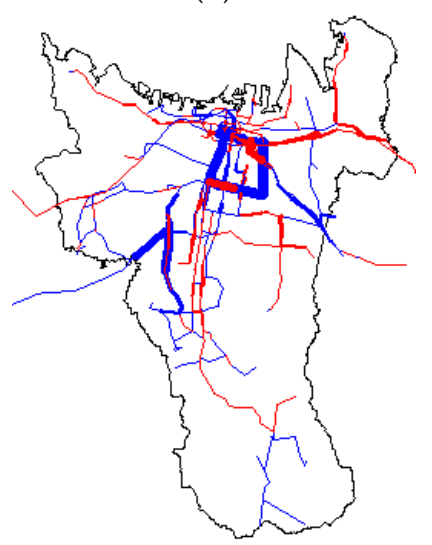

(d)

Figure 8. Difference in the expected daily number of passengers on public transport with and without network redesign (a) N1-N0 for BAU scenario, (b) N2-N0 for BAU scenario, (c) N1-N0 for Draconic scenario, and (d) N2-N0 for Draconic scenario. The red lines indicate links where the redesigned network is expected to have fewer public transport users than the current network, and the blue lines indicate links where the redesigned network is expected to have more users than the current network.

Figure 9 illustrates differences between the numbers of public transit trips predicted with and without network redesign. Figure 8a shows, for the BAU case, the difference between the numbers of trips predicted in the N1 network-redesign scenario and in the N0 baseline scenario; here blue pixels indicate locations from which more trips are expected to originate under N1 than under N0. Figure 8b similarly plots the difference between N2 and N0 predictions under BAU. Figure 8c,d show similar plots for the Draconic scenario. We see no prominent distinctions between results for N1 and N2, alhtough N2 seems slightly more effective at increasing the number of public transit trips originating from the city 
center. In the Draconic plots we see a significant uptick in transit journeys originating from the southwest population cluster under network-redesign scenarios.

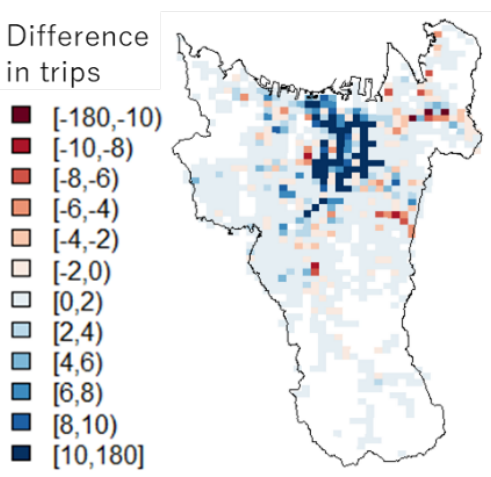

(a)

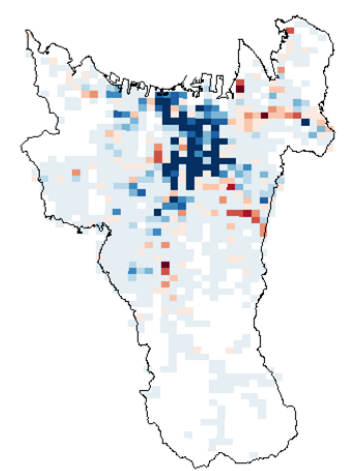

(b)

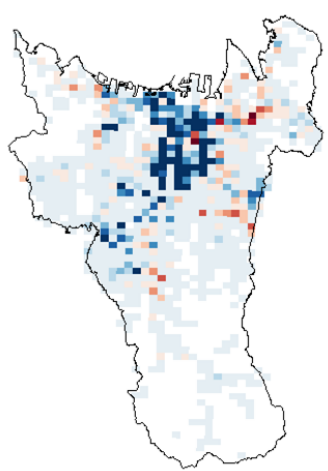

(c)

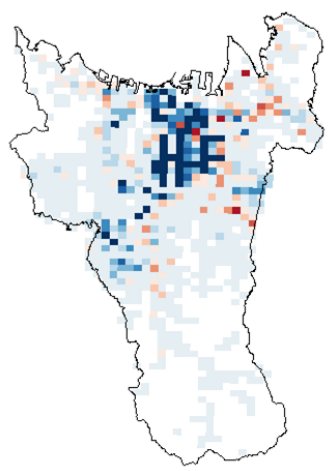

(d)

Figure 9. Differences between the numbers of public transport trips predicted with and without network redesign. (a) BAU N1-N0; (b) BAU N2-N0; (c) Draconic N1-N0; (d) Draconic N2-N0. Blue pixels indicate locations from which more public transit journeys are predicted to originate under network-redesign scenarios as compared to the baseline (network unchanged) scenario.

Table 4 shows how the average number of public transit users, the average distance walked by public transit users, and the volume of vehicular $\mathrm{CO}_{2}$ emissions vary under various network and population scenarios. For $\mathrm{CO}_{2}$ emissions we consider two scenarios: (a) vehicle emission factors in 2050 remain unchanged from 2010 values, and (b) vehicle emission factors in 2050 are halved compared to 2010 values [40].

Table 4. Dependence of various transportation statistics on population and network scenarios.

\begin{tabular}{|c|c|c|c|c|c|c|c|c|c|}
\hline & \multicolumn{3}{|c|}{2010} & \multicolumn{3}{|c|}{2050 BAU } & \multicolumn{3}{|c|}{ 2050_Draconic } \\
\hline & No & N1 & N2 & No & N1 & N2 & No & N1 & N2 \\
\hline Average transit ridership & 13.2 & 14.8 & 14.6 & 7.0 & 8.1 & 8.0 & 6.5 & 7.8 & 7.9 \\
\hline Walking distance $(\mathrm{km} /$ person/day) & 1.09 & 1.07 & 1.07 & 1.06 & 1.04 & 1.04 & 1.13 & 1.14 & 1.15 \\
\hline $\mathrm{CO}_{2}$ emission $(2010, \mathrm{~N} 0=100 \%)$ & \multirow{2}{*}{$100 \%$} & \multirow{2}{*}{$99.3 \%$} & \multirow{2}{*}{$99.7 \%$} & $73.2 \%$ & $72.9 \%$ & $73.0 \%$ & $60.9 \%$ & $60.4 \%$ & $60.4 \%$ \\
\hline & & & & $37.1 \%$ & $37.0 \%$ & $37.0 \%$ & $30.9 \%$ & $30.7 \%$ & $30.6 \%$ \\
\hline
\end{tabular}

We first note that the average occupancy rate for public transport, which in 2010 takes values of 13 or more, decreases by 2050 to just 7 (BAU) or 6.5 (Draconic) (in the N0 scenario). Table 3 shows that the ratio of public transit journeys to automobile journeys is higher in Draconic than in BAU. Average transit ridership is lower in the Draconic scenario because of its smaller overall population and its greater frequency of walking journeys, which arises from concentration of population in residential clusters.

The walking distance of public transport users is slightly higher in the Draconic scenario. Compared to the BAU scenario, this walking distance reflects lower average vehicle speeds due to the geographical concentration of residential locations, which results in relatively more public transport trips with long walking distances.

In addition, taking $2010 \mathrm{CO}_{2}$ emissions in the $\mathrm{N} 0$ scenario as a baseline $(100 \%), \mathrm{CO}_{2}$ emissions fall by 2050 to $73 \%$ in the BAU scenario and $60 \%$ in the Draconic scenario. (This is for emissions scenario (a), i.e., no improvement in vehicle technology.) In addition to the effects of population decline, the Draconic scenario predicts decreased emissions due to lower demand for automobile travel, as travel distances become shorter due to residential concentration and more frequent walking journeys. In emissions scenario (b), in which vehicle emissions are cut in half thanks to innovative vehicle technologies such as electrification, $\mathrm{CO}_{2}$ emissions decrease further to $37 \%$ in the BAU scenario and $31 \%$ in the 
Draconic scenario. In contrast, differences in public transit use rates for different network scenarios are negligible.

\section{Discussion and Conclusions}

In this study, we focused on the midsized Japanese city of Takamatsu and its goal of redesigning its transit system to better accommodate the needs of its declining and aging population. To investigate how Takamatsu's transit system reforms may impact the city's future, we used MATSim and a traffic-demand model to predict transportation trends for the year 2050, considering multiple possible scenarios for land-use regulations and transit system redesign.

Among the conclusions to emerge from the results of our analysis were the following insights. (1) Population decline will reduce road congestion, increasing the level of service (LOS) of car use and thus decreasing use of public transportation. (2) Redesigning public transit networks has the effect of increasing the LOS of public transit in areas where it is already in high demand. This, in turn, has the effect of increasing public transit use. (3) Spatially compact population distributions can worsen road congestion and increase use of public transportation. (4) Urban compactification and the redesign of public transit networks can have synergistic effects that increase use of public transportation. (5) The average occupancy of public transport vehicles in 2050 will be significantly lower than in 2010. (6) Scenarios involving spatially compact population distributions may result in increased walking distances for public transit users. (7) Redesigning public transit networks has negligible consequences for $\mathrm{CO}_{2}$ emissions. However, urban compactification has a major impact on reducing $\mathrm{CO}_{2}$ emissions.

These results suggest that, without effective transportation policy and careful urban planning, the convenience of automobiles will increase-and use of public transportation may decrease- even as far into the future as 2050, amid an aging population. In Japan, the number of traffic accidents involving the elderly is on the rise, and many local governments are taking measures to encourage older citizens to surrender their drivers' licenses. However, in the absence of measures to guarantee mobility for elderly citizens via public transportation and other means, only a tiny percentage of older citizens will agree to stop driving. Thus, measures to encourage the surrender of driver's licenses are not an effective strategy for addressing the problem of traffic safety for the elderly. Automobile safety technology has made significant improvements, and technologies such as driver assistance and automated driving are advancing day by day. However, ensuring higher safety levels will require coordination with the infrastructure side-a challenge for which technology may not even be widely available in 2050. Thus, urban planning measures—such as programs to guarantee mobility for older citizens via public transportation, as well as policies to produce compact, concentrated residential areas-will be of central importance.

We also note that the prevalence of lifestyle-related diseases tends to be higher in areas with high automobile dependence. The mortality rate of diabetes in Kagawa Prefecture, where Takamatsu is located, was 16.3 per 100,000 people in 2017, about $45 \%$ higher than the national average of 11.2. As public transportation journeys decrease and automobile journeys increase, walking distances will also decrease, possibly increasing health risks for society. Interestingly, transit system reform decreases the distance walked by public transportation users in the BAU scenario, but increases walking distances in the Draconic scenario. This discrepancy is due to the combined effects of various factors, including the decreased automobile traffic and increased frequency of transit journeys observed in the Draconic scenario. This result demonstrates the importance of coordination between transportation policy and land-use policy.

For $\mathrm{CO}_{2}$ reduction, innovations in vehicle technology are clearly essential, but our analysis indicates that population decline and land-use inducement are also effective. However, the Japanese government's target of an $80 \%$ reduction by 2050 is not achievable under the scenarios assumed in this study; additional measures will be required. Thus, 
urban structure guidance and transit system reform must be thought of as $\mathrm{CO}_{2}$ reduction measures, although not ones offering significant impacts on their own.

In view of the above discussion, we can say that public transportation and landuse policies combine to exert influence on various social issues, including traffic safety, health, and the environment. This study demonstrated that traffic microsimulation via agent-based models is an effective tool for studying countermeasures to address various societal problems related to cities and transportation. A variety of demographic scenarios predict declining and aging populations for many cities around the world, posing challenges that span a wide range of social, economic, and environmental domains. Land-use policies and transportation policies affect regional issues in various ways, and the trafficmicrosimulation approach of this study can be used to evaluate and analyze these policies from various perspectives.

This study did not attempt to coordinate land-use scenarios with the redesign of public transportation networks. Scenarios such as Transit Oriented Development, which encourages development around public transport nodes, may induce users to adopt public transport more enthusiastically. On the other hand, the effectiveness of such locationguidance policies has been problematic in many countries, including Japan. In this study, location scenarios were provided exogenously; a land-use transportation model that considers interactions between transportation demand and choice of location would be a good candidate for a strategy to analyze location-guidance policies.

Since changes in land use are more long-term than changes in transportation demand [41], it is essential to consider location-guidance measures with an eye toward the timing of people's residential choices to guide urban structures. For this purpose, land-use microsimulations that account for the life stages of agents can be effective. In particular, shrinking societies will see an increase in the number of vacant houses-thus bringing negative externalities to surrounding houses, reducing the density of traffic demand, and decreasing the viability of public transportation. Controlling the proliferation of such vacant houses, and mitigating the decreasing density of demand for public transportation, requires urban spatial strategies with a long-term perspective. Microsimulation can be an effective tool in dealing with such problems-a topic we reserve for future work.

Author Contributions: Conceptualization, M.K.; methodology, M.K.; software, M.K., Y.G.; validation, M.K. and Y.G.; formal analysis, M.K. and Y.G.; investigation, M.K., T.T. and T.S.; resources, M.K.; data curation, M.K., Y.G.; writing—original draft preparation, M.K.; writing—review and editing, M.K., T.T. and T.S.; visualization, M.K.; supervision, M.K., T.T. and T.S.; project administration, M.K.; funding acquisition, M.K. All authors have read and agreed to the published version of the manuscript.

Funding: This work was partly supported by JSPS Grants-in-Aid for Scientific Research (KAKENHI) 16KK0013 and 21H01456, Science and Technology Research Partnership for Sustainable Development (SATREPS) JPMJSA1704, and JSPS and DAAD under the Japan-Germany Research Cooperative Program JPJSBP120183515.

Acknowledgments: We thank Rolf Moeckel, Carlos Llorca, Nico Kuehnel, and Ana T. Moreno (Professorship for Modeling Spatial Mobility, Department of Civil, Geo and Environmental Engineering, Technical University of Munich) for invaluable assistance and for helpful discussions on applications of land-use and transport modeling. Needless to say, all errors are solely the responsibility of the authors.

Conflicts of Interest: The authors declare no conflict of interest. The funders had no role in the design of the study; in the collection, analyses, or interpretation of data; in the writing of the manuscript, or in the decision to publish the results. 


\section{References}

1. United Nations, Department of Economic and Social Affairs. Population Division. In World Urbanization Prospects. The 2018 Revision; United Nations: New York, NY, USA, 2019.

2. Alberti, V.; Alonso Raposo, M.; Attardo, C.; Auteri, D.; Ribeiro Barranco, R.; Batista, E.; Silva, F.; Benczur, P.; Bertoldi, P.; Bono, F.; et al The Future of Cities: Opportunities, Challanges and the Way Forward; Publications Office of the European Union: Luxembourg, 2019.

3. Kii, M. Projecting future populations of urban agglomerations around the world and through the 21st century. NPJ Urban Sustain. 2021, 1, 10. [CrossRef]

4. Horni, A.; Nagel, K.; Axhausen, K.W. The Multi-Agent Transport Simulation MATSim; Ubiquity Press: London, UK, 2016.

5. Guihaire, V.; Hao, J.-K. Transit network design and scheduling: A global review. Transp. Res. Part A Policy Pract. 2008, 42, 1251-1273. [CrossRef]

6. Holmgren, J. Meta-analysis of public transport demand. Transp. Res. Part A Policy Pract. 2007, 41, 1021-1035. [CrossRef]

7. Currie, G. Quantifying spatial gaps in public transport supply based on social needs. J. Transp. Geogr. 2010, 18, 31-41. [CrossRef]

8. Mindell, J.S.; Ergler, C.; Hopkins, D.; Mandic, S. Taking the bus? Barriers and facilitators for adolescent use of public buses to school. Travel Behav. Soc. 2021, 22, 48-58. [CrossRef]

9. Müller, S.; Tscharaktschiew, S.; Haase, K. Travel-to-school mode choice modelling and patterns of school choice in urban areas. J. Transp. Geogr. 2008, 16, 342-357. [CrossRef]

10. Böcker, L.; van Amen, P.; Helbich, M. Elderly travel frequencies and transport mode choices in Greater Rotterdam, the Netherlands. Transportation 2016, 44, 831-852. [CrossRef]

11. Alvarez, F.J.; Fierro, I. Older drivers, medical condition, medical impairment and crash risk. Accid. Anal. Prev. 2008, 40, 55-60. [CrossRef]

12. Lyman, J.M.; McGwin, G., Jr.; Sims, R.V. Factors related to driving difficulty and habits in older drivers. Accid. Anal. Prev. 2001, 33, 413-421. [CrossRef]

13. McGwin, G., Jr.; Chapman, V.; Owsley, C. Visual risk factors for driving difficulty among older drivers. Accid. Anal. Prev. 2000, 32, 735-744. [CrossRef]

14. Vance, D.E.; Roenker, D.L.; Cissell, G.M.; Edwards, J.D.; Wadley, V.G.; Ball, K.K. Predictors of driving exposure and avoidance in a field study of older drivers from the state of Maryland. Accid. Anal. Prev. 2006, 38, 823-831. [CrossRef] [PubMed]

15. Li, H.; Raeside, R.; Chen, T.; McQuaid, R.W. Population ageing, gender and the transportation system. Res. Transp. Econ. 2012, 34, 39-47. [CrossRef]

16. Oxley, J.; Whelan, M. It cannot be all about safety: The benefits of prolonged mobility. Traffic Inj. Prev. 2008, 9, 367-378. [CrossRef] [PubMed]

17. Kemperman, A.; Timmermans, H. Environmental Correlates of Active Travel Behavior of Children. Environ. Behav. 2014, 46, 583-608. [CrossRef]

18. Visser, M.; Pluijm, S.M.F.; Stel, V.S.; Bosscher, R.J.; Deeg, D.J.H. Physical activity as a determinant of change in mobility performance: The Longitudinal Aging Study Amsterdam. J. Am. Geriatr. Soc. 2002, 50, 1774-1781. [CrossRef]

19. Binder, E.F.; Schechtman, K.B.; Ehsani, A.A.; Steger-May, K.; Brown, M.; Sinacore, D.R.; Yarasheski, K.E.; Holloszy, J.O. Effects of exercise training on frailty in community-dwelling older adults: Results of a randomized, controlled trial. J. Am. Geriatr. Soc. 2002, 50, 1921-1928. [CrossRef]

20. Strawbridge, W.J.; Deleger, S.; Roberts, R.E.; Kaplan, G.A. Physical activity reduces the risk of subsequent depression for older adults. Am. J. Epidemiol. 2002, 156, 328-334. [CrossRef]

21. Delbosc, A.; Currie, G. Exploring the relative influences of transport disadvantage and social exclusion on well-being. Transp. Policy 2011, 18, 555-562. [CrossRef]

22. Haustein, S.; Siren, A. Seniors' unmet mobility needs-How important is a driving licence? J. Transp. Geogr. 2014, 41, 45-52. [CrossRef]

23. Kim, J.; Schmöcker, J.-D.; Nakamura, T.; Uno, N.; Iwamoto, T. Integrated impacts of public transport travel and travel satisfaction on quality of life of older people. Transp. Res. Part A Policy Pract. 2020, 138, 15-27. [CrossRef]

24. White, P.; Farrington, J. Bus and coach deregulation and privatization in Great Britain, with particular reference to Scotland. J. Transp. Geogr. 1998, 6, 135-141. [CrossRef]

25. Ellis, C.J.; Silva, E.C.D. British Bus Deregulation: Competition and Demand Coordination. J. Urban Econ. 1998, 43, 336-361. [CrossRef]

26. Szeto, W.Y.; Jiang, Y. Transit route and frequency design: Bi-level modeling and hybrid artificial bee colony algorithm approach. Transp. Res. Part B Methodol. 2014, 67, 235-263. [CrossRef]

27. Lee, Y.J.; Vuchic, V.R. Transit network design with variable demand. J. Transp. Eng. 2005, 131, 1-10. [CrossRef]

28. Ngamchai, S.; Lovell, D.J. Optimal time transfer in bus transit route network design using a genetic algorithm. J. Transp. Eng. 2003, 129, 510-521. [CrossRef]

29. Tom, V.M.; Mohan, S. Transit route network design using frequency coded genetic algorithm. J. Transp. Eng. 2003, 129, 186-195. [CrossRef]

30. Farber, S.; Morang, M.Z.; Widener, M.J. Temporal variability in transit-based accessibility to supermarkets. Appl. Geogr. 2014, 53, 149-159. [CrossRef] 
31. Kujala, R.; Weckström, C.; Mladenović, M.N.; Saramäki, J. Travel times and transfers in public transport: Comprehensive accessibility analysis based on Pareto-optimal journeys. Comput. Environ. Urban Syst. 2018, 67, 41-54. [CrossRef]

32. Calthorpe, P. The Next American Metropolis: Ecology, Community, and the American Dream; Princeton Architectural Press: New York, NY, USA, 1993.

33. Tamakloe, R.; Hong, J.; Tak, J. Determinants of transit-oriented development efficiency focusing on an integrated subway, bus and shared-bicycle system: Application of Simar-Wilson's two-stage approach. Cities 2021, 108, 102988. [CrossRef]

34. Nasri, A.; Zhang, L. The analysis of transit-oriented development (TOD) in Washington, D.C. and Baltimore metropolitan areas. Transp. Policy 2014, 32, 172-179. [CrossRef]

35. Tamakloe, R.; Hong, J. Assessing the efficiency of integrated public transit stations based on the concept of transit-oriented development. Transp. A Transp. Sci. 2020, 16, 1459-1489. [CrossRef]

36. Moeckel, R. Constraints in household relocation: Modeling land-use/transport interactions that respect time and monetary budgets. J. Transp. Land Use 2017, 10, 1-18. [CrossRef]

37. Llorca, C.; Silva, C.; Kuehnel, N.; Moreno, A.; Zhang, Q.; Kii, M.; Moeckel, R. Integration of Land Use and Transport to Reach Sustainable Development Goals: Will Radical Scenarios Actually Get Us There? Sustainability 2020, 12, 9795. [CrossRef]

38. Mitchell, R.B.; Rapkin, C. Urban Traffic; Columbia University Press: New York, NY, USA, 1954.

39. McFadden, D. Modelling the choice of residential location. Transp. Res. Rec. 1977, 673, 72-77.

40. Kii, M. Reductions in $\mathrm{CO}_{2}$ emissions from passenger cars under demography and technology scenarios in Japan by 2050. Sustainability 2020, 12, 6919. [CrossRef]

41. Wegener, M. The future of mobility in cities: Challenges for urban modelling. Transp. Policy 2013, 29, 275-282. [CrossRef] 